\title{
Small molecules in combination with conventional chemotherapeutic drugs: Light at the end of the tunnel?
}

\author{
MARTIN LEINUNG, CLEMENS CUNY, MARC DIENSTHUBER, TIMO STÖVER and JENS WAGENBLAST \\ ENT Department, Medical School, Goethe University, Frankfurt am Main, Hessen D-60590, Germany
}

Received May 14, 2012; Accepted August 15, 2012

DOI: $10.3892 / \mathrm{ol} .2012 .883$

\begin{abstract}
Recent studies have shown BI2536 and bortezomib to be effective in squamous cell carcinoma of the head and neck (SCCHN) cell lines. In this systemic in vitro study, we examined the antitumor effect of the small molecules BI2536 and bortezomib in combination with cisplatin or docetaxel in nine squamous cell carcinoma cell lines, most of head and neck origin. Dose escalation studies were performed with these cell lines using bortezomib, BI2536, cisplatin and docetaxel in cell line-specific concentrations. Growth inhibitory and proapoptotic effects were measured quantitatively using cytohistology and the Human Apoptosis Array kit. The combination of bortezomib and BI2536 with cisplatin or docetaxel showed a significantly higher antiproliferative and apoptotic activity in all SCCHN cell lines investigated compared with single agent cisplatin or docetaxel alone $(\mathrm{P} \leq 0.021)$. Combination of conventional chemotherapeutic drugs, such as cisplatin and docetaxel, with small molecules in the clinical setting may enhance the antitumor activity of these agents and may lead to less toxic side-effects and a more effective cancer therapy.
\end{abstract}

\section{Introduction}

Squamous cell carcinoma of the head and neck (SCCHN) is among the 10 most common types of cancer worldwide and arises from the surface epithelium of the upper-aerodigestive tract, including the oral cavity (1). As well as extensive tobacco and alcohol abuse, various epidemiological studies have revealed HPV-infection to be an independent risk factor in the development of SCCHN (2-4). The advent of chemotherapeutical drug regimes to treat head and neck cancer in the early 1980s changed a number of therapeutical paradigms. Previously, most patients with head and neck cancer of a higher tumor stage were treated either by surgery and

Correspondence to: Dr Jens Wagenblast, ENT Department, University Hospital, Theodor-Stern-Kai 7, Frankfurt am Main, Hessen D-60590, Germany

E-mail: jens.wagenblast@kgu.de

Key words: bortezomib, BI2536, cisplatin, docetaxel, squamous cell head and neck carcinoma cell lines, growth inhibition, apoptosis postoperative radiotherapy or by definitive radiotherapy. In more recent years, induction chemotherapy became a matter of interest as a treatment option in modern oncology (5). Although remission rates were often associated with severe side-effects, including nephrotoxicity and cardiovascular complications, cisplatin and docetaxel remain the most commonly used cytotoxic agents in the treatment of patients with SCCHN (6-8). However, these serious side-effects often require a reduction in dose or even discontinuation of chemotherapy. Although therapeutic treatment options have become more refined in recent decades, the prognosis of SCCHN remains poor. Therefore, one of the great challenges currently is to identify new, well-tolerated drug regimes which do not compromise the antitumor effect. Previously, several studies demonstrated that the proteasome inhibitor bortezomib was a prime candidate for drug development, not only in hematological malignancies, but also in solid cancers, including SCCHN (9-11). Other studies have shown further that bortezomib may be utilized to overcome cisplatin resistance in squamous cell carcinoma (12). In a previous systemic in vitro investigation, we showed that the polo-likekinase-1 (PLK1) inhibitor BI2536 had a marked antitumor effect in a large number of SCCHN cell lines (Wagenblast et al, unpublished data).

In order to address the need of developing new cancer treatment regimes, the aim of the present study was to evaluate the antitumor effects of a combination of the small molecules bortezomib and BI2536 with the conventional chemotherapeutic drugs cisplatin and docetaxel in nine tumor cell lines of squamous carcinoma origin.

\section{Materials and methods}

Nine squamous carcinoma cell lines, most of head and neck origin, were tested in the present study. A-431 cells were obtained from ATCC (American Type Culture Collection, Manassas, VA, USA). The PE/CA-PJ 15, PE/CA-PJ 41, PE/CA-PJ 49 and PE/CA-PJ 34 cell lines were obtained from ECACC (European Collection of Cell Cultures, Salisbury, UK) and Cal-27 and Kyse-140 cells from DSMZ GmbH (Braunschweig, Germany). CLS-354 and UM-SCC-14 C cells were obtained from Cell Lines Service (CLS; Eppelheim, Germany). A fibroblast cell line (human praeputium), used as a control cell line, was a gift from the Department of Dermatology, University Hospital (Frankfurt am Main, 
Table I. Cell line-specific drug concentrations of bortezomib, BI2536, cisplatin and docetaxel.

Concentration

\begin{tabular}{|c|c|c|c|c|}
\hline \multirow[b]{2}{*}{ Tumor cell line } & \\
\hline & Cisplatin $(\mu \mathrm{M})$ & Docetaxel (nM) & Bortezomib $(\mu \mathrm{M})$ & $\mathrm{BI} 2536(\mathrm{nM})$ \\
\hline PE/CA-PJ 15 & 1.56 & 2.5 & 2.50 & 2.50 \\
\hline PE/CA-PJ 34 & 1.56 & 2.5 & 5.00 & 2.50 \\
\hline PE/CA-PJ 41 & 0.19 & 5.0 & 2.50 & 2.50 \\
\hline PE/CA-PJ 49 & 1.56 & 15.0 & 1.25 & 2.50 \\
\hline CLS 354 & 1.56 & 10.0 & 1.25 & 2.50 \\
\hline UM-SCC-14 C & 1.56 & 10.0 & 2.50 & 2.50 \\
\hline Cal-27 & 0.39 & 15.0 & 2.50 & 2.50 \\
\hline Kyse-140 & 3.125 & 5.0 & 2.50 & 2.50 \\
\hline A-431 & 0.78 & 15.0 & 2.50 & 2.50 \\
\hline
\end{tabular}

Germany). Bortezomib (Velcade ${ }^{\circledR}$ ) was supplied by Millenium Pharmaceuticals Inc. (Cambridge, MA, USA) and Johnson \& Johnson Pharmaceuticals (Raritan, NJ, USA). BI2536 was provided by Boehringer Ingelheim GmbH (Vienna, Austria). Squamous carcinoma cell lines were cultivated according to the supplier's instructions with antibiotics at $37^{\circ} \mathrm{C}$ in the cell type-specific Quantum 263 medium with L-glutamine (PAA Laboratories $\mathrm{GmbH}$, Pasching, Austria). Cells were seeded in 96-multiwell plates ( $1 \times 10^{5}$ cells/well) and, following incubation for $24 \mathrm{~h}$, the cells were treated with cisplatin or docetaxel alone or in combination with bortezomib and BI2536 for 24, 48 and $76 \mathrm{~h}$, respectively. In the experiments, bortezomib, BI2536, cisplatin and docetaxel were used in each cell line at a fixed, cell line-specific concentration that had produced maximum growth inhibition in previous systematic investigations in our laboratory. The concentration for bortezomib ranged from 1.25 to $5 \mu \mathrm{M}$. The concentration for all cell lines investigated was $2.5 \mathrm{nmol} / 1$ for BI2536, showing maximal growth inhibition in our previous dose escalation studies. Dosage of cisplatin ranged from 0.19 to $3.125 \mu \mathrm{M}$ and docetaxel from 2.5 to $15 \mathrm{nM}$ (Table I). The number of cells was determined by counting cells in a Rosenthal chamber at 24, 48 and $72 \mathrm{~h}$ after treatment. Apoptosis was detected by microscopic cytohistology as well as using the Human Apoptosis Array kit (R\&D Systems, Abingdon, UK) as described previously $(13,14)$.

Each experiment was performed in triplicate. For statistical analysis, a Wilcoxon test for matched pairs (dependent samples) was performed using SPSS 19.0 software for Windows. $\mathrm{P}<0.05$ was considered to indicate a statistically significant result.

\section{Results}

Nine squamous carcinoma cell lines, most of head and neck origin, were tested in this study. Following incubation for $24 \mathrm{~h}$, the cells were treated with cisplatin and docetaxel alone or with a combination of bortezomib and BI2536 for 24, 48 and $76 \mathrm{~h}$. Compared with the untreated control groups, the proteasome inhibitor bortezomib, the PLK-1inhibitor BI2536, cisplatin and docetaxel had a significant antiproliferative and apoptotic effect when used as single agent treatments in all nine tumor cell lines $(\mathrm{P}=0.008)$. The combination of bortezomib/BI2536 and cisplatin showed

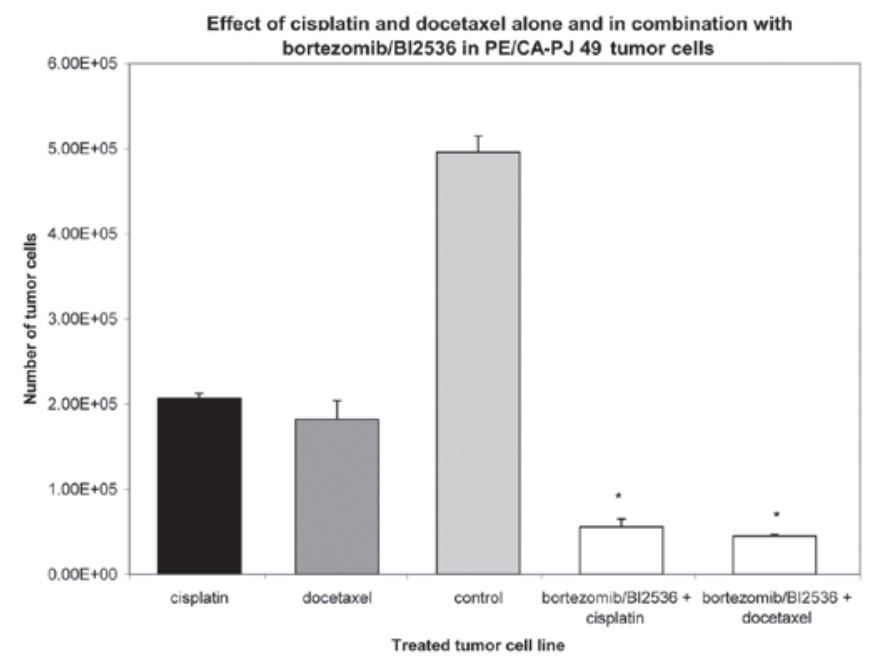

Figure 1. Growth inhibitory effect of cisplatin or docetaxel alone and in combination with bortezomib/BI2536 at a fixed cell line-specific concentration as shown in Table I after $72 \mathrm{~h}$ treatment in the PE/CA-PJ 49 tumor cell line. The untreated tumor cells (light grey column) served as a control and were incubated according to the supplier's instructions with antibiotics at $37^{\circ} \mathrm{C}$ in the cell type-specific Quantum 263 medium with L-glutamine. The absolute tumor cell numbers in the treated and control cell lines were determined in a Rosenthal chamber at $72 \mathrm{~h}$ after treatment or incubation with Quantum 263, respectively. Mean values of three independent experiments with standard deviation are shown. Significant differences between single agent and combination treatment and untreated controls are indicated by asterisks. Combination treatment of bortezomib/BI2536+cisplatin or +doectaxel significantly inhibited cell proliferation compared with mono drug therapy with cisplatin or docetaxel alone $(\mathrm{P} \leq 0.021)$.

a significantly higher antiproliferative activity compared with cisplatin alone $(\mathrm{P}=0.008)$. The same phenomenon was observed in the combination of bortezomib/BI2536 with docetaxel compared with docetaxel monotherapy $(\mathrm{P}=0.021$; Figs. 1 and 2). Apoptosis was detected by microscopic cytohistology as well as using the Human Apoptosis Array kit (R\&D Systems), detecting pro caspase 3 as a typical molecular apoptosis marker.

The combination of the conventional chemotherapeutic drugs cisplatin and docetaxel with small molecules in this in vitro examination significantly enhanced the antitumor activity of these agents. 


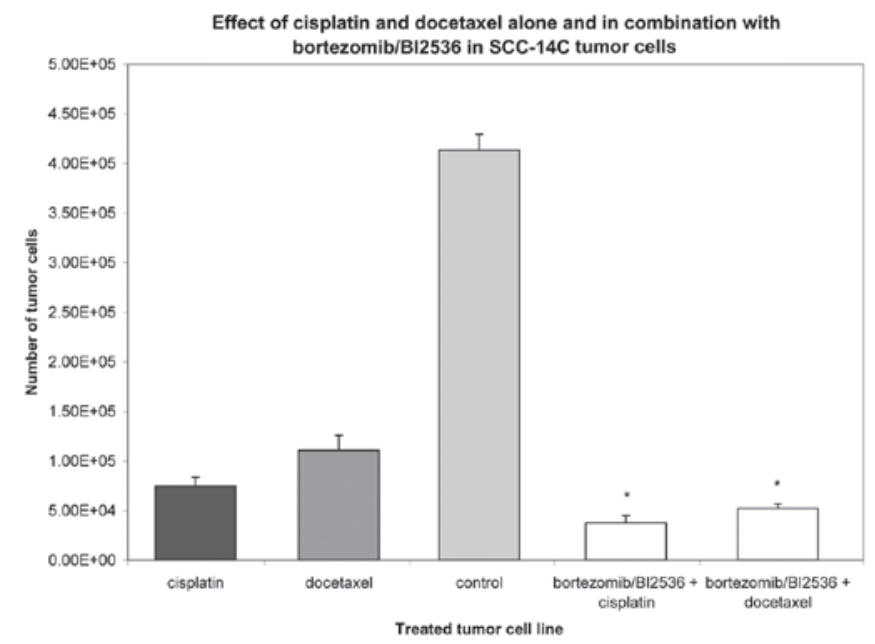

Figure 2. Growth inhibitory effect of cisplatin or docetaxel alone and in combination with bortezomib/BI2536 at a fixed cell line-specific concentration as shown in Table I after $72 \mathrm{~h}$ treatment in the SCC-14C tumor cell line. The untreated tumor cells (light grey column) served as a control and were incubated according to the supplier's instructions with antibiotics at $37^{\circ} \mathrm{C}$ in the cell type-specific Quantum 263 medium with L-glutamine. The absolute tumor cell numbers in the treated and control cell lines were determined in a Rosenthal chamber at $72 \mathrm{~h}$ after treatment or incubation with Quantum 263, respectively. Mean values of three independent experiments with standard deviation are shown. Significant differences between single agent and combination treatment and untreated controls are indicated by asterisks Combination treatment of bortezomib/BI2536+cisplatin or +doectaxel sig nificantly inhibited cell proliferation compared with mono drug therapy with cisplatin or docetaxel alone $(\mathrm{P} \leq 0.021)$.

\section{Discussion}

Various molecularly targeted approaches have been investigated in SCCHN patients in the search of improved selectivity and toxicity. Targets that are worth considering include growth factor receptors, signal transduction proteins, kinases, such as PLK1, and proteins involved in the degradation of kinases, such as the proteasome $(15,16)$. Previous studies have demonstrated the marked growth inhibitory and apoptotic effects of bortezomib, a small molecular weight reversible inhibitor of the intracellular 26S proteasome, in SCCHN $(10,17)$. Bortezomib acts primarily by inhibition of the $\mathrm{NF} \kappa \mathrm{B}$ signaling pathway, although the complete molecular mechanism leading to the antitumor action of this proteasome inhibitor remains unidentified $(18,19)$. BI2536 is a further selective and potent small molecule that inhibits PLK1, which is a key player in processes such as cell division and checkpoint regulation in mitosis (20). Approximately $80 \%$ of human tumors express high levels of PLK-1 transcripts, which are correlated with poor prognosis (20-23). PLK inhibitors, such as BI2536 and BI6727, interfere with several stages of mitosis, including spindle formation and chromosome separation, thus inducing a mitotic chaos leading to a disruption of cell cycle progression. In the present study, we showed the enhanced antitumor effect of a combination of two small molecules which affect different signaling pathways. The drug combination of bortezomib/BI2536 with cisplatin showed a significantly higher antiproliferative activity compared with cisplatin alone $(\mathrm{P}<0.008)$. The same phenomenon was observed in the combination of bortezomib/BI2536 with docetaxel compared with docetaxel monotherapy $(\mathrm{P}=0.021)$. In summary, the results of our systemic in vitro experiments have demonstrated the growth inhibitory and proapoptotic effect of a combination regime consisting of the two small molecules bortezomib/ BI2536 in combination with conventional chemotherapeutic drugs, cisplatin and docetaxel, in SCCHN cell lines for the first time.

With regard to the combination of two small molecules, bortezomib/BI2536, enhancing the antiproliferative effect of both cytotoxic agents, cisplatin and docetaxel, it appears to be possible to reduce the doses of the conventional drugs and thus to reduce the severe side-effects of these regimes in the future.

\section{Acknowledgements}

The authors thank Boehringer Ingelheim $\mathrm{GmbH}$ for providing BI2536. The authors thank Erika Weith for excellent technical support.

\section{References}

1. Mehanna H, Paleri V, West CM and Nutting C: Head and neck cancer - Part 1: Epidemiology, presentation, and prevention. BMJ 341: c4684, 2010.

2. D'Souza G, Kreimer AR, Viscidi R, Pawlita M, Fakhry C, Koch WM, et al: Case-control study of human papillomavirus and oropharyngeal cancer. N Engl J Med 356: 1944-1956, 2007.

3. Pantel M and Guntinas-Lichius O: Laryngeal carcinoma: epidemiology, risk factors and survival. HNO 60: 32-40, 2012 (In German).

4. Wittekindt C, Wagner S and Klussmann JP: HPV-associated head and neck cancer. The basics of molecular and translational research. HNO 59: 885-892, 2011 (In German).

5. Lefebvre JL, Andry G, Chevalier D, Luboinski B, Collette L, Traissac L, et al; for the EORTC Head and Neck Cancer Group: Laryngeal preservation with induction chemotherapy for hypopharyngeal squamous cell carcinoma: 10-year results of EORTC trial 24891. Ann Oncol: Apr 6, 2012 (Epub ahead of print).

6. Forastiere AA, Leong T, Rowinsky E, Murphy BA, Vlock DR, DeConti RC and Adams GL: Phase III comparison of high-dose paclitaxel + cisplatin + granulocyte colony-stimulating factor versus low-dose paclitaxel + cisplatin in advanced head and neck cancer: Eastern Cooperative Oncology Group Study E1393. J Clin Oncol 19: 1088-1095, 2001.

7. Ramesh G and Reeves WB: TNF-alpha mediates chemokine and cytokine expression and renal injury in cisplatin nephrotoxicity. J Clin Invest 110: 835-842, 2002.

8. Pabla $\mathrm{N}$ and Dong Z: Cisplatin nephrotoxicity: mechanisms and renoprotective strategies. Kidney Int 73: 994-1007, 2008.

9. Fribley A, Zeng Q and Wang CY: Proteasome inhibitor PS-341 induces apoptosis through induction of endoplasmic reticulum stress-reactive oxygen species in head and neck squamous cell carcinoma cells. Mol Cell Biol 24: 9695-9704, 2004.

10. Wagenblast J, Hambek M, Baghi M, Gstöttner W, Strebhardt K, Ackermann $\mathrm{H}$ and Knecht R: Antiproliferative activity of bortezomib alone and in combination with cisplatin or docetaxel in head and neck squamous cell carcinoma cell lines. J Cancer Res Clin Oncol 134: 323-330, 2008.

11. Sunwoo JB, Chen Z, Dong G, Yeh N, Crowl Bancroft C, Sausville E, et al: Novel proteasome inhibitor PS-341 inhibits activation of nuclear factor-kappa B, cell survival, tumor growth, and angiogenesis in squamous cell carcinoma. Clin Cancer Res 7: 1419-1428, 2001.

12. Fribley AM, Evenchik B, Zeng Q, Park BK, Guan JY, Zhang H, et al: Proteasome inhibitor PS-341 induces apoptosis in cisplatinresistant squamous cell carcinoma cells by induction of Noxa. $\mathrm{J}$ Biol Chem 281: 31440-31447, 2006.

13. Datta D, Banerjee P, Gasser M, Waaga-Gasser AM and Pal S: CXCR3-B can mediate growth-inhibitory signals in human renal cancer cells by down-regulating the expression of heme oxygenase-1. J Biol Chem 285: 36842-36848, 2010. 
14. Ray RB, Raychoudhuri A, Steele R and Nerurkar P: Bitter melon (Momordica charantia) extract inhibits breast cancer cell proliferation by modulating cell cycle regulatory genes and promotes apoptosis. Cancer Res 70: 1925-1931, 2010.

15. Wagenblast J, Baghi M, Arnoldner C, Bisdas S, Gstöttner W, Ackermann $\mathrm{H}$, et al: Effect of bortezomib and cetuximab in EGF-stimulated HNSCC. Anticancer Res 28: 2239-2243, 2008.

16. Reuter CW, Morgan MA and Eckardt A: Targeting EGF-receptorsignalling in squamous cell carcinomas of the head and neck. $\mathrm{Br}$ J Cancer 96: 408-416, 2007.

17. Wagenblast J, Baghi M, Arnoldner C, Bisdas S, Gstöttner W, Ackermann $\mathrm{H}$, et al: Cetuximab enhances the efficacy of bortezomib in squamous cell carcinoma cell lines. J Cancer Res Clin Oncol 135: 387-393, 2009.

18. Milano A, Iaffaioli RV and Caponigro F: The proteasome: a worthwhile target for the treatment of solid tumours? Eur J Cancer 43: 1125-1133, 2007.

19. Adams J: The development of proteasome inhibitors as anticancer drugs. Cancer Cell 5: 417-421, 2004.
20. Schoffski P, Blay JY, De Greve J, Brain E, Machiels JP, Soria JC, et al: Multicentric parallel phase II trial of the polo-like kinase 1 inhibitor BI 2536 in patients with advanced head and neck cancer, breast cancer, ovarian cancer, soft tissue sarcoma and melanoma. The first protocol of the European Organization for Research and Treatment of Cancer (EORTC) Network Of Core Institutes (NOCI). Eur J Cancer 46: 2206-2215, 2010.

21. Schmit TL and Ahmad N: Regulation of mitosis via mitotic kinases: new opportunities for cancer management. Mol Cancer Ther 6: 1920-1931, 2007.

22. Strebhardt K and Ullrich A: Targeting polo-like kinase 1 for cancer therapy. Nat Rev Cancer 6: 321-330, 2006.

23. Knecht R, Elez R, Oechler M, Solbach C, von Ilberg C and Strebhardt K: Prognostic significance of polo-like kinase (PLK) expression in squamous cell carcinomas of the head and neck. Cancer Res 59: 2794-2797, 1999. 